\title{
Late outcomes after radial artery versus saphenous vein grafting during reoperative coronary artery bypass surgery
}

\author{
Anoar Zacharias, MD, ${ }^{\mathrm{a}}$ Thomas A. Schwann, MD, ${ }^{\mathrm{b}}$ Christopher J. Riordan, MD, ${ }^{\mathrm{b}}$ Samuel J. Durham, MD, ${ }^{\mathrm{b}, \mathrm{c}}$ \\ Aamir S. Shah, MD, ${ }^{\text {,cc }}$ Milo Engoren, MD, ${ }^{b}$ and Robert H. Habib, $\mathrm{PhD}^{\mathrm{a}, \mathrm{d}}$
}

Objective: We investigated whether use of radial artery versus saphenous vein grafts during coronary artery bypass grafting reoperations is associated with a significant long-term survival benefit.

Methods: We reviewed a series of 347 consecutive coronary artery bypass grafting reoperations (1996-2007; $270[78 \%$ ] male patients; age, $65.3 \pm 9.2$ years). Internal thoracic artery grafts were used in $248(71 \%)$ patients at the time of the first coronary artery bypass grafting operation and in $154(44 \%)$ patients at reoperation. Patients were grouped based on whether a functional radial artery graft was present after coronary artery bypass grafting reoperation (radial artery cohort, $\mathrm{n}=203$ [59\%]) or not (saphenous vein cohort, $\mathrm{n}=144$ [41\%]). Median time to reoperation was similar for the radial artery (10.3 years) and saphenous vein (10.1 years) cohorts $(P=.55)$. Angiographic data were used to ascertain the number and type of grafts that remained functional from initial coronary artery bypass grafting. Survival data ( $\leq 12$ years) were time segmented based on multiphase hazard modeling at 90 days, and late survival was then analyzed by using proportional hazard Cox regression, with risk adjustment based on a radial artery-use propensity score computed from 48 covariates, including time to reoperation, month of surgical intervention, and total arterial and vein grafts after reoperation. Propensity-matched and propensity quintile comparisons were also done.

Results: Follow-up was similar for the radial artery versus saphenous vein cohorts ( $5.7 \pm 3.4$ vs $5.8 \pm 4.0$ years, $P=.86$ ), and 112 (50 in the radial artery and 62 in the saphenous vein cohorts) deaths were documented. Early mortality ( $\leq 90$ days) did not differ for the radial artery $(7.4 \%)$ and saphenous vein $(12.5 \%)$ cohorts $(P=.14)$. Unadjusted late outcomes were superior for the radial artery versus saphenous vein cohorts, with survival of $97.3 \%$ versus $92.9 \%, 84.9 \%$ versus $77.2 \%$, and $74.1 \%$ versus $60.3 \%$ at 1,5 , and 10 years, respectively. Propensity-adjusted radial artery survival was superior, with a hazard ratio of $0.58(P=.04)$, and this result was confirmed in a propensity-matched comparison.

Conclusions: We conclude that the use of radial artery as opposed to saphenous vein grafting for reoperative coronary artery bypass grafting, either with or without concomitant internal thoracic artery grafts, is associated with a substantial improvement in late survival. This benefit is likely derived from the increased overall number of arterial grafts. (J Thorac Cardiovasc Surg 2010;139:1511-8)

\section{Supplemental material is available online.}

\footnotetext{
$\overline{\text { From Yvonne Viens, SGM, Research Institute }}{ }^{\text {a }}$-Saint Vincent Mercy Medical Center, Toledo, Ohio; the Division of Cardiothoracic Surgery, ${ }^{b}$ the Regional Heart and Vascular Center at Saint Vincent Mercy Medical Center, Toledo, Ohio; and the Departments of Surgery ${ }^{\mathrm{c}}$ and Medicine, ${ }^{\mathrm{d}}$ University of Toledo College of Medicine, Toledo, Ohio.

This research is supported by departmental and institutional funds.

Disclosures: None.

Received for publication March 9, 2009; revisions received July 3, 2009; accepted for publication July 29, 2009; available ahead of print Oct 12, 2009.

Address for reprints: Robert $\mathrm{H}$. Habib, PhD, Cardiovascular and Pulmonary Research, Yvonne Viens, SGM, Research Institute, St Vincent Mercy Medical Center, 2222 Cherry St, MOB2, Suite 1250, Toledo, OH 43608 (E-mail: Robert_Habib@ mhsnr.org).

0022-5223/\$36.00

Copyright (c) 2010 by The American Association for Thoracic Surgery

doi:10.1016/j.jtcvs.2009.07.068
}

Evidence of the benefits of arterial grafts on late outcomes of coronary artery bypass grafting (CABG) has accumulated over the past 2 decades. ${ }^{1-7}$ The left internal thoracic artery (LITA)/left anterior descending artery (LAD) graft has become the standard of care in patients undergoing primary CABG when LAD disease is present. ${ }^{1,2}$ Several groups have also reported that further improvement in late survival is achieved by using additional arterial grafts, such as a second internal thoracic artery (ITA) ${ }^{3,4}$ or radial artery (RA) graft, ${ }^{5-8}$ as opposed to the conventional operation combining LITA/LAD with saphenous vein (SV) grafting.

Currently, there is a paucity of data on what is the optimal grafting method in case of reoperative CABG, particularly related to late outcomes. This has been confounded, in recent years, by the fact that many, if not a majority, of the patients presenting for repeat CABG might have had at least 1 ITA graft used during their first operation. The re-emergence of the RA graft and its demonstrated survival benefit after primary CABG put forth the possibility of a similar late RA 


$$
\begin{aligned}
& \text { Abbreviations and Acronyms } \\
& \begin{aligned}
\text { CABG } & =\text { coronary artery bypass grafting } \\
\text { ITA } & =\text { internal thoracic artery } \\
\text { LAD } & =\text { left anterior descending artery } \\
\text { LITA } & =\text { left internal thoracic artery } \\
\text { RA } & =\text { radial artery } \\
\text { SV } & =\text { saphenous vein }
\end{aligned}
\end{aligned}
$$

benefit after $\mathrm{CABG}$ reoperation. In this study we analyzed the $\mathrm{CABG}$ reoperation experience at our institution with the primary aim of testing the hypothesis that use of RA grafting for repeat $\mathrm{CABG}$ will confer a significant long-term survival benefit when compared with SV grafting.

\section{MATERIALS AND METHODS}

This investigation is a retrospective analysis of a prospectively collected cardiac surgery database approved by the institutional review board, and informed consent was waived for this study. The database is collected and reported in accordance with the Society of Thoracic Surgeons' national database criteria.

\section{Study Population}

Patients undergoing reoperative CABG between January 1, 1996, and December 31, 2007, were considered for inclusion in this study. Patients were excluded if they underwent concomitant valve surgery, aortic surgery, or both during their operation or if they received ITA grafts exclusively $(\mathrm{n}=8)$. The final study population consisted of 347 patients $(270$ [78\%] male patients; age, $65.3 \pm 9.2$ years) divided into 2 subcohorts irrespective of their ITA grafting during reoperation (Table 1): the RA cohort consisted of $203(59 \%)$ patients who either received 1 or more RA grafts at reoperation ( $\mathrm{n}=200$, with or without additional SV grafts) or had remaining patent RA grafts from the first CABG $(n=3)$, and the SV cohort consisted of 144 (41\%) patients with SV and no RA grafting at reoperation. Patients' demographic, comorbidity, and operative data for the RA and SV cohorts are summarized in Table 2. Annual volumes and their breakdown to the RA and SV cohorts are provided in Table E1.

The overall cohort included $283(82 \%)$ isolated CABGs, whereas 64 underwent $\mathrm{CABG}$ combined with other noncardiac (eg, lung or carotid operations) or cardiac (eg, the maze procedure or ventricular aneurysm repair) procedures. Cardiopulmonary bypass was used in a large majority of patients, with only $23(6.6 \%)$ of 347 study patients undergoing offpump surgery. Over the 1996-2007 study period, the annual volumes varied between 9 and 48 cases per year (median, 32 cases). The initial CABG operation occurred over a period of 3 decades (1973-2005). The annual distribution of initial CABG and the corresponding increasing rate of ITA use at the time of the first operation are shown in Figure 1 (top). Median time to reoperation was similar for the RA (10.3 years) and SV (10.1 years) cohorts (Figure 1, bottom). A large majority of patients underwent their first reoperation CABG $(\mathrm{n}=333$ [96\%]) compared with 12 who underwent their second (7 in the RA cohort and 5 in the SV cohort) and 2 (both in the RA cohort) who underwent their third reoperations.

\section{Data Collection}

Coronary catheterization reports before the index CABG reoperation were retrieved, and the status of previously placed grafts, including type of conduit and coronary targets, was recorded. For this study, a coronary graft was considered to be an anastomotic failure in case of (1) complete occlusion, (2) stenosis of $75 \%$ or greater, or (3) presence of extensive conduit narrowing or "string sign." Long-term all-cause mortality data were secured from our service patient follow-up and verified from individual patient queries of the United States Social Security Death Index database (http://ssdi.genealogy.rootsweb.com) in September 2008. Database records were updated for missing death information when necessary. Allowing for a 3-month lag in the Social Security Death Index database, this corresponds to a minimum of 6 (December 2007 patients) and a maximum of 150 (January 1996 patients) months' follow-up.

\section{Coronary Grafts}

A summary of the number and type of completed grafts during the initial CABG operation of the RA and SV reoperative CABG cohorts is provided in Table 1. This table also shows the respective failure rates of these original grafts, as observed at the time of the index redo CABG operation. Expanded data, including the target-conduit use and graft failure data from the initial CABG operation, both combined and separated for the RA and SV cohorts, are provided in Tables E2 to E7. Lastly, grafting data at the index CABG reoperation are summarized for both cohorts in Table 2, whereas the related target-conduit use data from the reoperation are provided in Table E8. Note that for the 347 members of the total redo CABG population, 154 (44.3\%) had ITAs used at reoperation, and this was similar for the 2 study cohorts (RA vs SV, 87/203 [43\%] vs 67/144 [47\%]; $P>.2$; Table 2). At least 1 functional (patent) ITA graft was present in 179 (88\%) RA cohort and $118(82 \%)$ SV cohort patients after the CABG reoperation. The 200 RA cohort patients received 260 radial grafts (1.3 per patient) achieved by means of bilateral radial use in 37 patients and construction of sequential radial grafts in 21 patients.

\section{Surgical Technique}

The approach to reoperative CABG was similar to that seen in other studies. ${ }^{9,10}$ The surgical technique of RA harvesting and its intraoperative management in case of $\mathrm{CABG}$ reoperation was similar to that described for patients undergoing primary $\mathrm{CABG}^{5-8}$ Briefly, the presence of peripheral vascular disease was not a criterion for excluding patients from RA use per se. Hand collateral circulation and palmar arch status were assessed by using the modified Allen test and Doppler ultrasonography, respectively. Intraoperative plethysmography and oximetry were performed before establishing cardiopulmonary bypass. The RA was explored through a small incision, and harvesting was abandoned in case of small-vessel caliber, significant calcification, or both. Harvesting was done at the same time as the LITA dissection, with the RA removed as a pedicle without electrocautery (harmonic scalpel) and immersed in diluted papaverine. Hydrostatic and mechanical dilatation were not used to avoid intimal injury.

Bilateral RA harvesting was done in $37(18.5 \%)$ of the 200 patients undergoing reoperative CABG with RA grafts. RA use as a single graft was predominant, whereas sequential RA grafts anastomosed to 2 or 3 target vessels were used in $21(10.5 \%)$ patients. RA grafts were generally placed to target vessels greater than $1 \mathrm{~mm}$ in diameter, with a proximal stenosis of greater than $70 \%$ in a large majority of patients. The inflow into the sequential RA was in the overwhelming majority of cases from the aorta, unless aortic atherosclerosis or graft length issues precluded an RA to aorta anastomosis. The RA grafts coursed over the surface of the heart in gentle curves without acute angulation or kinking. The side-to-side anastomoses were constructed in 2 ways: (1) a diamond configuration in which the graft axis lies perpendicular to the axis of the target vessel or (2) a parallel configuration in which the graft and target axis are aligned. The target-vessel arteriotomy length in the diamond configuration was a function of the size of the RA and was tailored to prevent a seagull deformity. The distal anastomosis was constructed in either an anatomic (heel proximally or toe distally on the target vessel) or antianatomic (heel distally or toe proximally) fashion to facilitate a smooth course over the surface of the heart. The grafting strategy was predicated on maximizing the number of target vessels 
TABLE 1. Summary of "initial CABG" grafting data with corresponding failure rates at the time of reoperation*

\begin{tabular}{|c|c|c|c|c|c|c|}
\hline \multirow[b]{3}{*}{ Conduits } & \multicolumn{3}{|c|}{$\begin{array}{c}\text { RA at redo } \\
\text { operation }(n=200)\end{array}$} & \multicolumn{3}{|c|}{$\begin{array}{c}\text { SV/no RA at redo } \\
\text { operation }(n=147) \dagger\end{array}$} \\
\hline & \multirow[b]{2}{*}{ Grafts (n) } & \multicolumn{2}{|c|}{ Failed } & \multirow[b]{2}{*}{ Grafts (n) } & \multicolumn{2}{|c|}{ Failed } \\
\hline & & No. & $\%$ & & No. & $\%$ \\
\hline All types & 560 & 310 & 55 & 374 & 240 & 64 \\
\hline SV & 385 & 268 & 70 & 253 & 195 & 77 \\
\hline Arterial & 175 & 42 & 24 & 121 & 45 & 37 \\
\hline RA & 13 & 5 & 38 & 21 & 17 & $81 \dagger$ \\
\hline ITA (any) & 162 & 37 & 23 & 100 & 28 & 28 \\
\hline LITA & 150 & 31 & 21 & 92 & 23 & 25 \\
\hline RITA & 10 & 5 & 50 & 7 & 5 & 71 \\
\hline Free ITA & 2 & 1 & 50 & 1 & 0 & 0 \\
\hline
\end{tabular}

$C A B G$, Coronary artery bypass grafting; $R A$, radial artery; $S V$, saphenous vein; $I T A$, internal thoracic artery; LITA, left internal thoracic artery; RITA, right internal thoracic artery. *Related target-conduit use and graft failure data from the initial CABG operation, both combined and separated for the RA and SV cohorts, are provided in Tables E2 to E7. Target-conduit use data at the time of CABG reoperation are provided in Table E8. †Three of 147 "SV/no RA at redo operation" patients had 4 patent RA grafts from previous CABG operations. Therefore these 3 patients were included in the RA cohort for the purposes of outcomes analysis, including in Table 2 and Figures 3-5.

revascularized through the RA and was not intended to place the distal anastomosis to the best target with the best runoff. Over the course of the study period, based on emerging data documenting suboptimal results of RA durability in the right coronary artery system, RA use evolved such that RAs were placed almost exclusively in the left coronary artery distribution.

\section{Propensity Score Models}

The RA and SV redo CABG cohorts exhibited significant differences in their demographic, risk factor, and operative variables (Table 2). Such differences confound outcome comparisons in observational treatment groups. ${ }^{11}$ To minimize such confounding when comparing the effects of grafting methods on long-term survival, we used propensity score adjustment in which RA grafting was considered treatment. ${ }^{11,12}$ Briefly, the probability that a patient received RA grafts (or the RA-use propensity score) was defined by a propensity score derived from a nonparsimonious logistic multivariate model applied to all patients. Forty-eight variables (highly redundant variables were avoided) were entered into the nonparsimonious model, irrespective of their significance, which included the variables shown in Table 1. Two additional time-related variables were also included in the propensity model: (1) month of redo CABG entered as a continuous month-of-series variable (January 1996=1 up to December $2007=144$ ) to account for potential varying frequency of RA grafting over the study time period and (2) first-to-redo surgical interval as a continuous variable in years. Finally, the propensity model also included 3 variables defining the number of arterial (mostly ITA) and SV grafts from the initial $\mathrm{CABG}$ operation that were functional (patent or $<75 \%$ stenosis) at the time of reoperation. Including these variables in the model ensured that the survival comparisons are appropriately adjusted for the total number of grafts (and hence completeness of revascularization), and it accurately accounted for the total number of arterial versus venous grafts in the comparison groups. Expectedly, the resulting propensity scores were different (mean \pm standard deviation: $0.677 \pm 0.203$ [RA cohort] vs $0.455 \pm 0.207$ [SV cohort]; $P=.0000$ ]. The $\mathrm{C}$-statistic value for the propensity model was $0.79 \pm 0.02$, indicating excellent discrimination. This score was used in 3 complementary analyses: (1) risk-adjustment late survival comparisons based on the logit propensity score; (2) propensity
TABLE 2. Comparison of demographic, risk factor, and operative data for the RA versus SV redo CABG cohorts

\begin{tabular}{|c|c|c|c|}
\hline Variable/category & RA group & SV group & $P$ value \\
\hline No. of patients & 203 & 144 & \\
\hline \multicolumn{4}{|l|}{ Demographics } \\
\hline Male sex & $82 \%$ & $72 \%$ & .035 \\
\hline Age (y) & $65 \pm 9$ & $66 \pm 10$ & .067 \\
\hline Body mass Index $\left(\mathrm{kg} / \mathrm{m}^{2}\right)$ & $30.8 \pm 5.3$ & $28.5 \pm 5.2$ & .000 \\
\hline Body surface area $\left(\mathrm{m}^{2}\right)$ & $2.08 \pm 0.22$ & $1.99 \pm 0.22$ & .000 \\
\hline \multicolumn{4}{|l|}{ Preoperative data } \\
\hline Smoker & $69 \%$ & $69 \%$ & $>.2$ \\
\hline Current & $16 \%$ & $17 \%$ & $>.2$ \\
\hline Diabetes & $44 \%$ & $40 \%$ & $>.2$ \\
\hline Insulin dependent & $13 \%$ & $17 \%$ & $>.2$ \\
\hline High cholesterol & $88 \%$ & $76 \%$ & .004 \\
\hline Renal failure & $2.5 \%$ & $5.6 \%$ & .136 \\
\hline Hypertension & $86 \%$ & $85 \%$ & $>.2$ \\
\hline Peripheral vascular disease & $19 \%$ & $33 \%$ & .002 \\
\hline Cerebrovascular disease & $30 \%$ & $35 \%$ & $>.2$ \\
\hline Cerebrovascular accident & $13 \%$ & $9 \%$ & $>.2$ \\
\hline Previous myocardial infarction & $69 \%$ & $67 \%$ & $>.2$ \\
\hline Congestive heart failure & $12 \%$ & $9 \%$ & $>.2$ \\
\hline Arrhythmia (any) & $13 \%$ & $19 \%$ & .093 \\
\hline Chronic lung disease & $20 \%$ & $26 \%$ & $>.2$ \\
\hline NYHA classification (I-IV) & $2.98 \pm 0.87$ & $3.20 \pm 0.79$ & .027 \\
\hline Class III/IV & $74 \%$ & $84 \%$ & .032 \\
\hline Coronary vessel disease $(1,2,3)$ & $2.78 \pm 0.50$ & $2.73 \pm 0.57$ & $>.2$ \\
\hline Left main disease & $29 \%$ & $40 \%$ & .032 \\
\hline Ejection fraction $(\%)$ & $46 \pm 10$ & $47 \pm 9$ & $>.2$ \\
\hline IABP & $8 \%$ & $13 \%$ & .151 \\
\hline Previous PTCA & $50 \%$ & $41 \%$ & .157 \\
\hline Stent & $31 \%$ & $24 \%$ & .148 \\
\hline$\beta$-Blockers & $68 \%$ & $70 \%$ & $>.2$ \\
\hline ACE inhibitor & $50 \%$ & $43 \%$ & $>.2$ \\
\hline Aspirin & $87 \%$ & $79 \%$ & .062 \\
\hline \multicolumn{4}{|l|}{ Operative data } \\
\hline Emergency & $1.0 \%$ & $5.6 \%$ & .012 \\
\hline Multiple reoperations & $4.4 \%$ & $3.5 \%$ & $>.2$ \\
\hline Cardiopulmonary bypass (min) & $125 \pm 50$ & $115 \pm 74$ & .159 \\
\hline Crossclamp time (min) & $63 \pm 32$ & $49 \pm 33$ & .000 \\
\hline Off-pump & $4.9 \%$ & $9.0 \%$ & .131 \\
\hline Other cardiac procedure & $13.3 \%$ & $7.6 \%$ & .097 \\
\hline Other noncardiac procedure & $7.4 \%$ & $10 \%$ & $>.2$ \\
\hline \multicolumn{4}{|l|}{ Grafting data } \\
\hline ITA used & $43 \%$ & $47 \%$ & $>.2$ \\
\hline Left ITA & $19 \%$ & $28 \%$ & .061 \\
\hline Right ITA & $24 \%$ & $21 \%$ & $>.2$ \\
\hline SVG used & $75 \%$ & $100 \%$ & .000 \\
\hline RA used & $99 \%$ & $0 \%$ & .000 \\
\hline No. of grafts & $2.93 \pm 1.07$ & $2.48 \pm 0.87$ & .000 \\
\hline Arterial & $1.72 \pm 0.72$ & $0.49 \pm 0.55$ & .000 \\
\hline SV & $1.21 \pm 0.91$ & $1.99 \pm 0.81$ & .000 \\
\hline
\end{tabular}

$R A$, Radial artery; $S V$, saphenous vein; $C A B G$, coronary artery bypass grafting; $N Y H A$ New York Heart Association; IABP, intra-aortic balloon pump; $P T C A$, percutaneous transluminal coronary angioplasty; $A C E$, angiotensin-converting enzyme; ITA, internal thoracic artery; $S V G$, saphenous vein graft. 
ITA Utilization at Initial CABG Operation
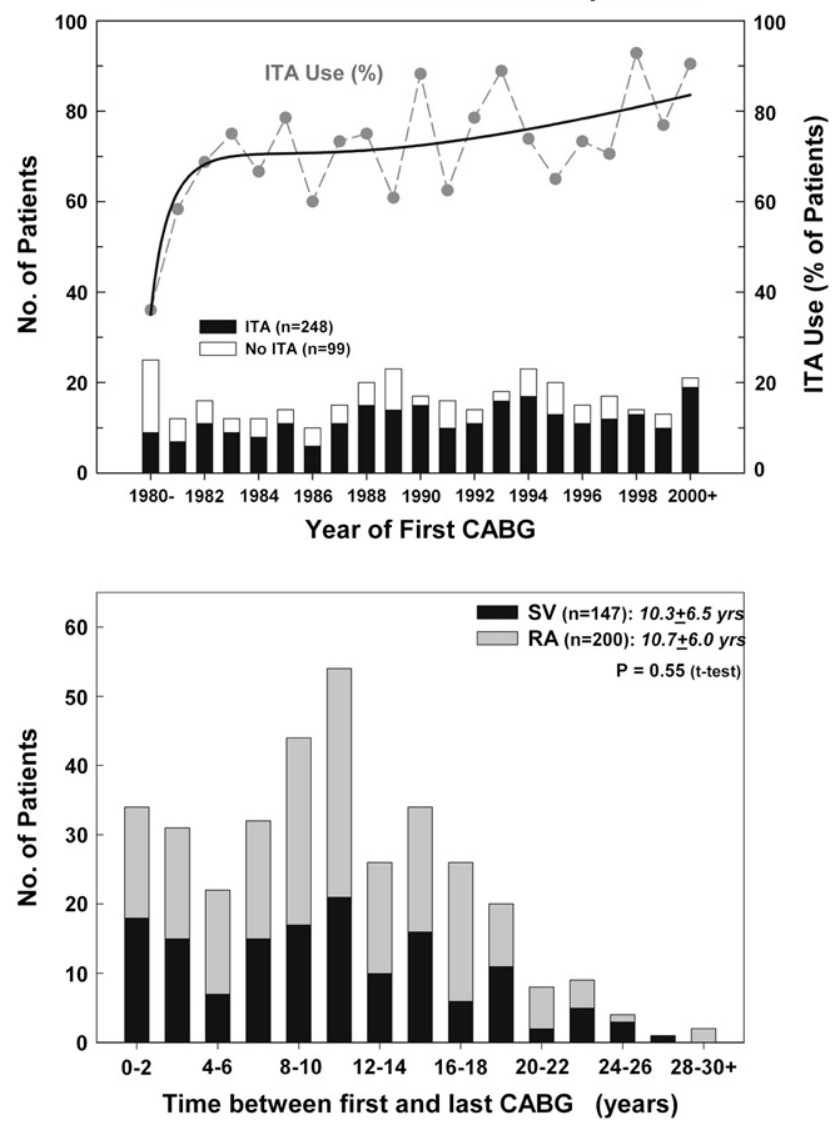

FIGURE 1. Top, Year of initial coronary artery bypass grafting $(C A B G)$ surgery data with the corresponding incidence of internal thoracic artery (ITA) grafting. Bottom, Interval between the first and reoperative CABG operations for the entire study population and its radial artery $(R A)$ and saphenous vein $(S V)$ subcohorts.

stratification (quintile)-based RA versus SV survival comparison; and (3) propensity-matched RA versus SV survival comparison.

\section{Data Analysis and Statistical Methods}

Continuous data were expressed as means \pm standard deviations. When applicable, univariate comparisons were done with $\chi^{2}$ or Fisher's exact tests for categorical variables and the unpaired $t$ test for continuous variables. Unadjusted survival comparisons for the baseline, propensitystratified (quintiles), and matched cohorts were done with Kaplan-Meier analysis, with statistical significance based on the log-rank (MantelCox) or Breslow (generalized Wilcoxon) tests. Late survival Cox regression analysis was performed on time-segmented data by using 90 days as a cutoff based on a multiphase model fit (Figure 2) that included an earlyphase (log-linear form) and a late (Weibull)-phase component. ${ }^{13}$ The grafting method's effects on survival after reoperative CABG were investigated by using comparisons of RA versus SV (or no radial) late survival with risk adjustment through the logit of the RA-use propensity score. Lastly, although ITA use was included in the propensity score calculation, the propensity-adjusted analyses were repeated, with ITA grafting at reoperation (yes/no) forced into the regression model for further confirmation of results. Statistical analysis was conducted with SPSS version 15.0 software (SPSS, Inc, Chicago, Ill). A $P$ value of less than .05 was used to indicate significance.
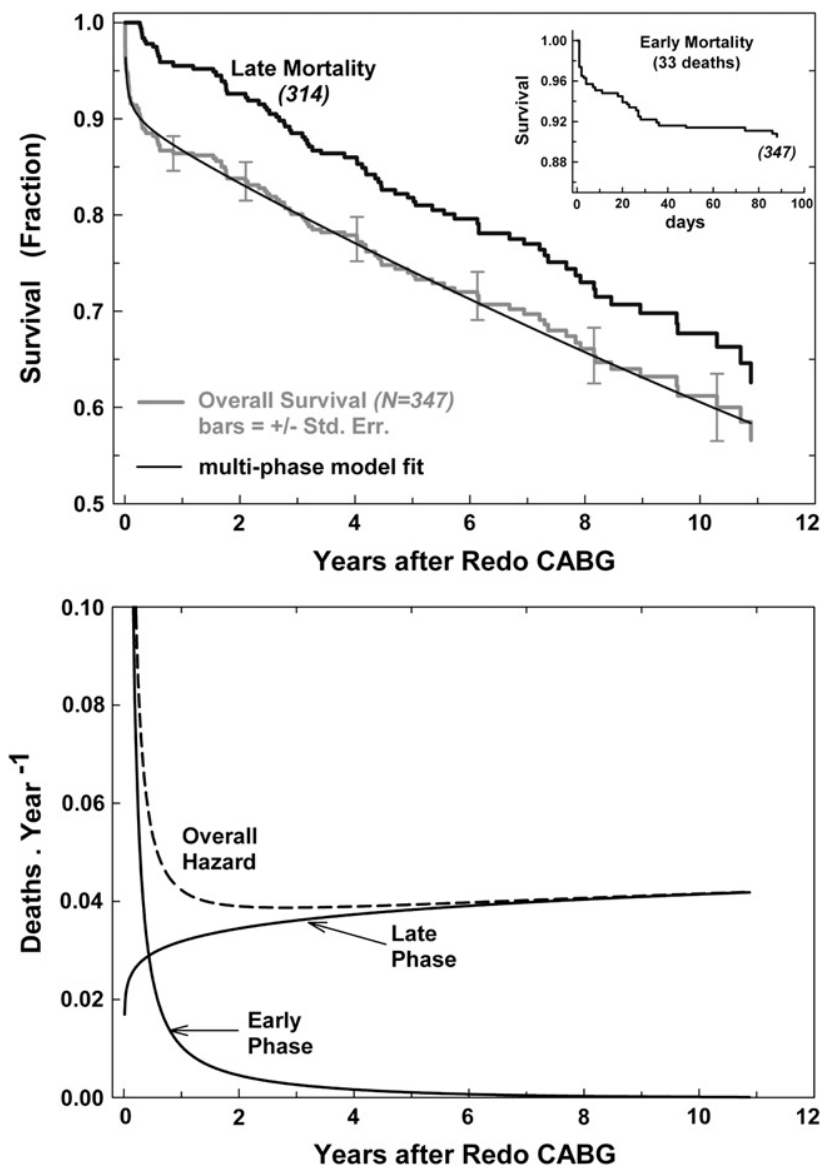

FIGURE 2. Top, Overall $(\mathrm{n}=347$, gray line $)$ and late $(\mathrm{n}=314$, black line) Kaplan-Meier survival for reoperative coronary artery bypass grafting $(C A B G)$. Error bars represent the standard error (Std. Err.) survival estimates at selected time points (1, 2, 4, 6, 8, and 10 years). The black line through the overall Kaplan-Meier data represents the multiphase model fit. The insert shows early-phase mortality. Bottom, Early, late, and overall hazard functions based on the multiphase model fit shown in the top panel. Early hazard values approached late hazard values at approximately 90 days, which was then used to time segment early and late survival.

\section{RESULTS}

Follow-up was similar for the RA versus SV cohorts (5.7 \pm 3.4 vs $5.8 \pm 4.0$ years, $P=.86$ ), and 112 (50 in the RA and 62 in the SV cohorts) deaths were documented. Early death within 90 days of surgical intervention occurred in $33(9.5 \%)$ patients and was not significantly different for the RA versus SV cohorts (15/203 [7.4\%] vs 18/144 $[12.5 \%], P=.14)$. The overall unadjusted late survival for the remaining 314 patients was $95.5 \%, 81.8 \%$, and $67.7 \%$ at 1,5 , and 10 years, respectively. The corresponding late outcomes were substantially better for the RA versus SV cohorts, with survival values of $97.3 \%$ versus $92.9 \%$ ( 1 year), $84.9 \%$ versus $77.2 \%$ (5 years), and $74.1 \%$ versus $60.3 \%$ (10 years; $P=.008$, Breslow; Figure 3, top). These 

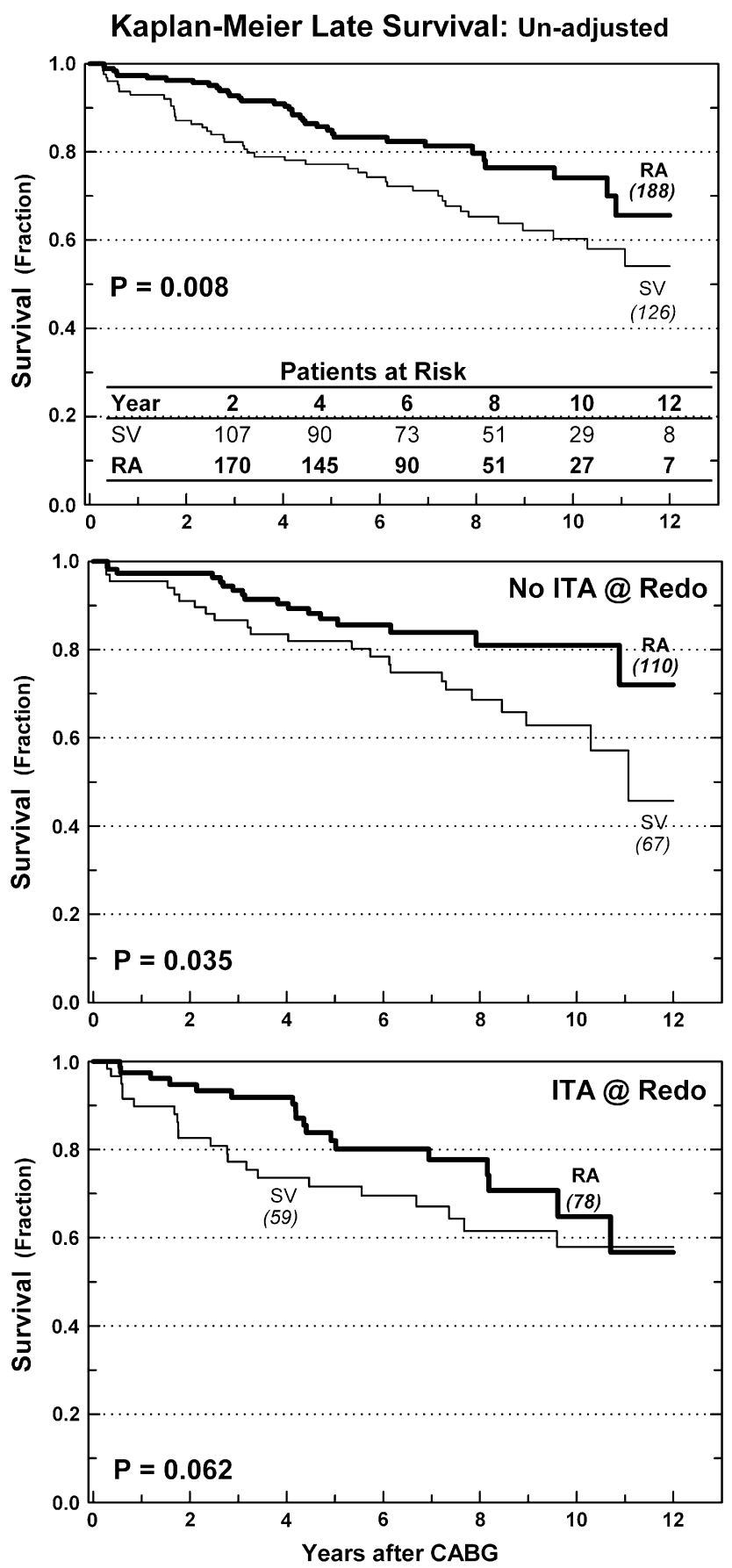

FIGURE 3. Comparison of unadjusted late survival after reoperative coronary artery bypass grafting $(C A B G)$ for patients with radial artery grafts $(R A)$ versus those with saphenous vein grafts $(S V)$ and no radial grafts. Top, All patients; middle, patients with no internal thoracic artery (ITA) grafts at reoperation; bottom, patients with ITA grafts at reoperation. $P$ values were determined by using the Breslow (generalized Wilcoxon) test.

superior RA results were more pronounced (Table 3) in patients not receiving ITA grafts at the time of reoperation (no ITA, $P=.035$; Figure 3 , middle) compared with those who did (ITA, $P=.062$; Figure 3 , bottom).
TABLE 3. Unadjusted and risk-adjusted (logit propensity) late ( $>90$ days) mortality hazard ratios using proportional hazard Cox regression analysis

\begin{tabular}{lcccc}
\hline Patient cohort* & RA (n) & SV (n) & $\begin{array}{c}\text { Hazard ratio } \\
(\mathbf{9 5} \% \mathbf{C I})\end{array}$ & $\boldsymbol{P}$ value \\
\hline $\begin{array}{l}\text { Unadjusted } \\
\quad \text { RA vs SV, all }\end{array}$ & 188 & 126 & $0.58(0.37-0.91)$ & .017 \\
$\quad$ patients & & & & \\
$\quad$ RA vs SV, no ITA & 110 & 67 & $0.45(0.27-0.96)$ & .038 \\
$\quad$ RA vs SV, ITA & 78 & 59 & $0.67(0.33-1.26)$ & .214 \\
Risk adjusted & & & & \\
$\quad$ RA vs SV & 188 & 126 & $0.58(0.35-0.98)$ & .041 \\
$\quad$ Logit (RA propensity & & & $0.99(0.80-1.25)$ & .991 \\
$\quad$ score) & & & & \\
$\quad$ RA vs SV & 188 & 126 & $0.58(0.35-0.98)$ & .041 \\
$\quad \begin{array}{l}\text { ITA, forced } \\
\text { Logit (RA propensity }\end{array}$ & & & $1.29(0.83-2.01)$ & .259 \\
$\quad$ score) & & & $1.00(0.80-1.26)$ & .975 \\
\hline
\end{tabular}

$R A$, Radial artery; $S V$, saphenous vein; $C I$, confidence interval; $I T A$, internal thoracic artery. *Thirty-three patients experiencing early death ( $\leq 90$ days) were excluded from analysis.

\section{Propensity-Adjusted Comparison (Late Survival)}

The risk-adjusted late survival comparisons through logit RA-use propensity score-adjusted Cox regression are summarized in Figure 4 and Table 3. The RA versus SV late survival risk-adjusted risk ratio was $0.58 \quad(95 \%$ confidence interval, $0.35-0.98 ; P=.04)$. Notably, this result is unchanged when ITA use at reoperation was additionally forced into the regression. Finally, to ascertain that the above late RA survival benefit was not confounded by whether a functional (patent) ITA graft was present after reoperation, we repeated the logit propensity-adjusted analysis limited to the 269 late ( $>90$ days) survivors (166 in the RA cohort and 103 in the SV cohort) with 1 or more functional ITA grafts after redo CABG. This analysis resulted in an unchanged risk-adjusted risk ratio (RA vs SV cohort) of 0.58 (95\% confidence interval, 0.34-0.99; $P=.047$ ).

\section{Propensity Quintiles Comparison (Overall Survival)}

Results of RA versus SV survival comparisons based on propensity quintile stratification are provided in Figure E1 and summarized in Table 4. For quintile I (only 18 RA cohort patients), RA and SV survivals were essentially identical, whereas a meaningful comparison was not possible for quintile V because group membership included only $4 \mathrm{SV}$ cohort patients. Alternatively, the RA subcohorts showed superior survival compared with their SV cohort counterparts for quintiles II $(P=.026)$, III $(P=.086)$, and IV $(P=.13)$.

\section{Propensity-Matched Comparison (Overall Survival)}

Ninety-seven $(47.8 \%)$ of 203 RA cohort patients were matched to $97(67.4 \%)$ of $144 \mathrm{SV}$ cohort counterparts based on the RA-use propensity score with similar matched group scores (SV vs RA cohort, $0.539 \pm 0.180$ vs $0.543 \pm 0.175$; 


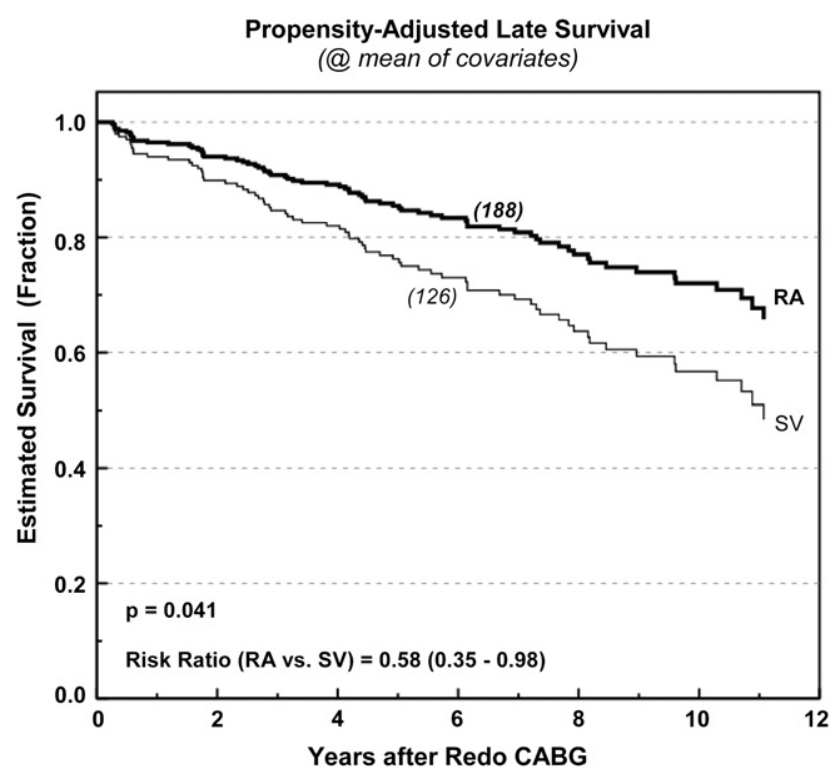

FIGURE 4. Comparison of risk-adjusted late coronary artery bypass grafting $(C A B G)$ survival after reoperative CABG for the radial artery $(R A)$ versus saphenous vein $(S V)$ grafting method subcohorts. Risk adjustment was done with an RA-use propensity score adjustment. The shown RA and SV survival patterns represent model predictions computed at the mean of covariates based on the Cox regression analysis results.

$P=.79)$. Here, too, the subsequent RA versus $\mathrm{SV}$ analysis exhibited superior RA survival in both the matched $(P=$ $.024)$ and unmatched $(P=.036)$ cohorts (Figure 5).

\section{Predictors of Late Reoperative CABG Survival}

Predictors of late mortality after redo $\mathrm{CABG}$ derived by means of multivariate Cox regression analysis included 5 patient factors (Tables 5 and E9]: increased age, lower ejection fraction, preoperative renal failure (worse), concomitant noncardiac surgery (worse), and RA grafting (better). These same variables continued to predict late survival when the propensity score was forced into the model to account for residual confounding.

\section{DISCUSSION}

Reoperation for myocardial revascularization remains a necessary treatment in some patients with coronary artery disease because of the recurrence of symptoms of coronary insufficiency. Vein graft attrition remains the primary cause for reoperations, and it is estimated that $50 \%$ to $60 \%$ of vein grafts will be severely compromised or occluded 10 years after bypass surgery. $9,10,14$ Current Society of Thoracic Surgeons statistics indicate that nearly $5 \%$ of the CABG procedures done in the United States are repeat surgical revascularizations. The role of risk factors has been investigated by many, and as in other series, ${ }^{9,10,15-17}$ our redo CABG cohort was characterized by a relatively high incidence of multiple risk factors (Table 2) and by the aggressive nature of their early-onset coronary artery disease given their relatively young age at the initial CABG operation (55 years [mean]) and at reoperation (65 years). Although characteristically a higher-risk cohort, advancements in reoperative techniques have favorably affected the surgical results. ${ }^{9,10}$ In this article we analyze the less studied potential effects of the grafting methods on long-term outcomes, specifically focusing on the choice between RA and SV conduits. Also, this patient series is distinct from previous reports exploring graft choice in redo $\mathrm{CABG}$ because a substantial majority of the patients had 1 or more ITA grafts during the first operation.

Our primary finding is that the choice of RA as opposed to SV grafting at reoperation did not affect hospital outcomes but was associated with a substantial risk-adjusted late survival benefit analogous to what was previously reported when the RA was used as a second arterial conduit $^{5,6}$ or to facilitate total arterial revascularization. ${ }^{7}$ These results are presumed to be in direct correlation to the reported better long-term patency of the RA compared with the SV. ${ }^{4,18-21}$ Importantly, the additional survival improvement was obtained in the presence of the substantial use of ITA grafts, both during the first CABG operation (248/347 [71\%]) and at reoperation (154/347 [44\%]). The analysis also accounted for the potential confounding effects caused by between-group differences in 2 important factors: (1) completeness of revascularization and (2) cumulative arterial versus vein grafting. ${ }^{7}$ Both of these factors depend on the total number of functional grafts from both the first and repeat operations. This was achieved by

TABLE 4. Summary of survival comparisons for RA versus SV propensity score quintile subcohorts*

\begin{tabular}{|c|c|c|c|c|c|c|c|}
\hline \multirow[b]{2}{*}{ Quintile group } & \multicolumn{2}{|c|}{ No. of patients } & \multicolumn{2}{|c|}{ 5-y Survival $(\% \pm \mathrm{SE})$} & \multicolumn{2}{|c|}{ 10-y Survival $(\% \pm$ SE $)$} & \multirow[b]{2}{*}{ Kaplan-Meier $\dagger P$ value } \\
\hline & $\mathbf{R A}$ & SV & $\mathbf{R A}$ & SV & $\mathbf{R A}$ & SV & \\
\hline $\mathrm{I}(\mathrm{n}=70)$ & 18 & 52 & $62.7 \pm 12.4$ & $66.7 \pm 6.6$ & $47.0 \pm 16.4$ & $47.6 \pm 7.5$ & .904 \\
\hline $\mathrm{II}(\mathrm{n}=70)$ & 27 & 43 & $92.0 \pm 5.5$ & $69.5 \pm 7.1$ & $81.8 \pm 10.8$ & $56.6 \pm 8.9$ & .026 \\
\hline III $(\mathrm{n}=70)$ & 41 & 29 & $78.2 \pm 6.9$ & $64.9 \pm 9.0$ & $78.2 \pm 6.9$ & $59.5 \pm 9.7$ & .086 \\
\hline $\mathrm{IV}(\mathrm{n}=70)$ & 54 & 16 & $85.9 \pm 5.0$ & $73.7 \pm 11.3$ & $78.2 \pm 7.1$ & $53.6 \pm 15.4$ & .132 \\
\hline $\mathrm{V}(\mathrm{n}=67)$ & 63 & 4 & $71.4 \pm 5.9$ & $50.5 \pm 25.0$ & $55.2 \pm 9.3$ & NA & .243 \\
\hline Overall $(\mathrm{n}=347)$ & 203 & 144 & $78.6 \pm 3.0$ & $67.5 \pm 3.9$ & $68.6 \pm 4.4$ & $52.8 \pm 4.8$ & .002 \\
\hline
\end{tabular}

$R A$, Radial artery; $S V$, saphenous vein; $S E$, standard error; $N A$, not available. *Corresponding Kaplan-Meier survival plots are shown in Figure E1. $\dagger$ Kaplan-Meier $P$ value is based on the Breslow test. 

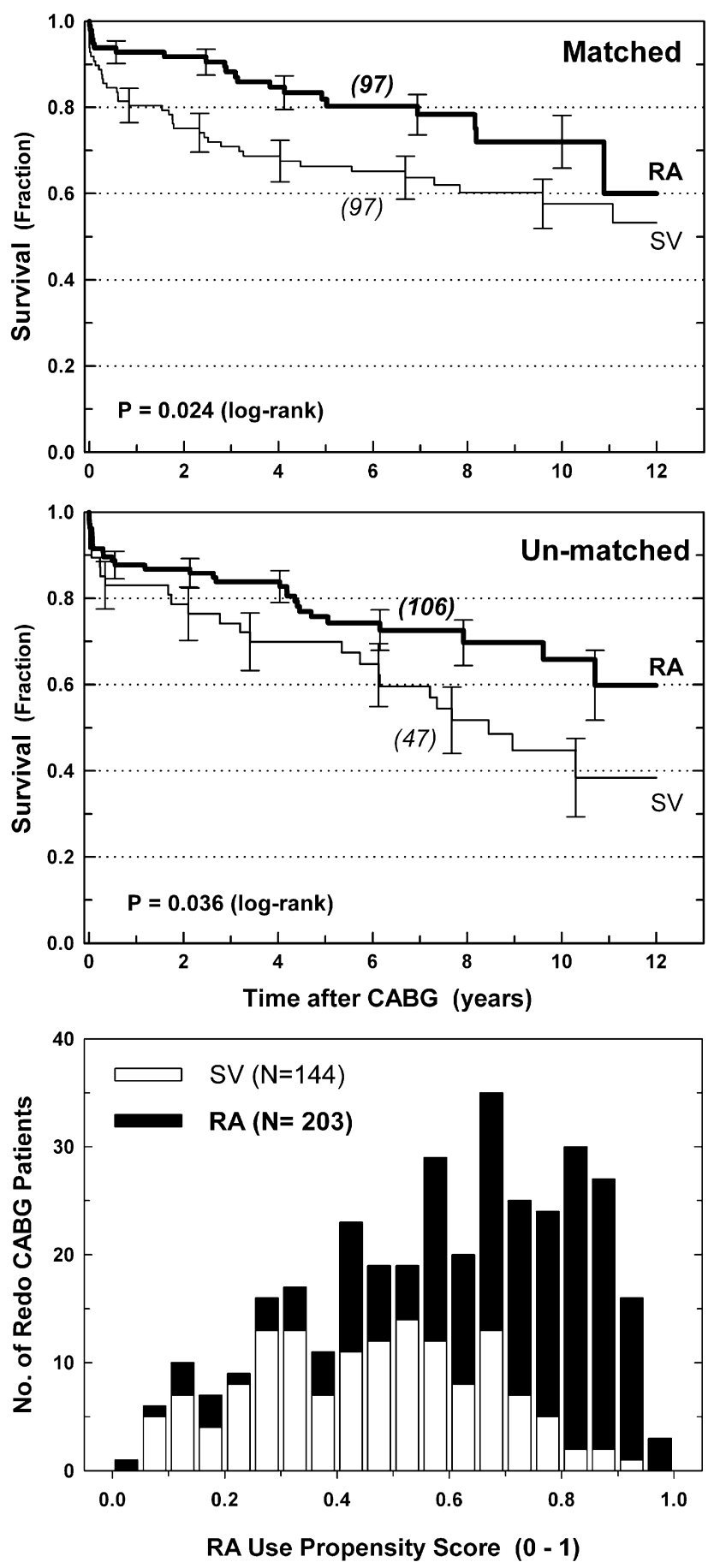

FIGURE 5. Kaplan-Meier survival comparison for matched (top, 97 patients each) and unmatched (middle) patients in the radial artery $(R A)$ versus saphenous vein $(S V)$ cohorts in whom matching was done with the RA-use propensity score. Bottom, Distribution of propensity scores among the RA (black bars) and SV (white bars) subcohorts. Error bars represent the standard error survival estimates at selected time points.

combining the patent grafts from the first operation (Table 1) with the new grafts and incorporating the cumulative grafting data along with the associated vessel disease in
TABLE 5. Predictors of late survival after redo CABG derived by means of proportional hazard Cox regression analysis

\begin{tabular}{lrcc}
\hline \multicolumn{1}{c}{ Variables } & Wald & $\begin{array}{c}\text { Risk ratio } \\
(\mathbf{9 5} \% \mathbf{C I})\end{array}$ & $\begin{array}{c}\text { Significance } \\
(\boldsymbol{P} \text { value })\end{array}$ \\
\hline Backward/forward selection & & & \\
RA graft (vs SV) & 4.54 & $0.59(0.37-0.96)$ & .033 \\
Ejection fraction (\%) & 9.35 & $0.96(0.94-0.99)$ & .002 \\
Other noncardiac procedure & 4.72 & $2.07(1.07-3.98)$ & .030 \\
Age (y) & 9.80 & $1.05(1.02-1.08)$ & .002 \\
Renal failure & 18.08 & $5.83(2.59-13.1)$ & .000 \\
Forced propensity score & & & \\
RA graft (vs SV) & 5.43 & $0.53(0.31-0.90)$ & .020 \\
Ejection fraction (\%) & 9.16 & $0.96(0.94-0.99)$ & .002 \\
Other noncardiac procedure & 5.16 & $2.15(1.11-4.17)$ & .023 \\
Age (y) & 10.51 & $1.05(1.02-1.08)$ & .001 \\
Renal failure & 18.92 & $6.27(2.74-14.4)$ & .000 \\
RA-use propensity & 0.90 & $1.13(0.88-1.45)$ & .343 \\
$\quad$ score (logit) & & & \\
\hline
\end{tabular}

Considered variables in addition to "RA graft (vs SV)" and "RA-use propensity score (logit)" included 3 continuous covariates ("Age [y]," "Body mass index $\left[\mathrm{kg} / \mathrm{m}^{2}\right]$,", and "Ejection fraction [\%]") and 20 categorical covariates: diabetes, insulin dependence, renal failure, high cholesterol, hypertension, peripheral vascular disease, cerebrovascular disease, chronic lung disease, history of myocardial infarction, congestive heart failure, arrhythmia, New York Heart Association class III/IV, left main disease, coronary vessel disease (1.2 or 3), emergency, off-pump coronary artery bypass grafting, other cardiac procedure, other noncardiac procedure, patent left internal thoracic artery (previous coronary artery bypass grafting), and number of arterial grafts (total). $C A B G$, Coronary artery bypass grafting; $C I$, confidence interval; $R A$, radial artery; $S V$, saphenous vein.

the propensity score model used for risk-adjusted survival calculations.

A voluminous number of reports have investigated early outcomes of reoperative CABG, including the effects of grafting approaches. ${ }^{22-26}$ Studies investigating the late effects of arterial and vein conduits in reoperative CABG are limited, and most of these report a late benefit of arterial (ITA or RA) over SV grafts. Loop and colleagues ${ }^{22}$ and Kaul and associates ${ }^{23}$ reported late outcomes from large observational redo $\mathrm{CABG}$ series, showing a $10 \%$ survival benefit at 10 years using a single ITA as opposed to an SV at reoperation. However, concerns have been raised regarding incomplete risk adjustment for the notable differences in demographics and risk factors between the 2 groups. ${ }^{27}$ Weintraub and coworkers ${ }^{24}$ did not find a similar survival benefit with the use of ITAs at reoperation. Dougenis and Brown $^{25}$ analyzed the long-term results of 103 patients undergoing reoperative $\mathrm{CABG}$ (all with $\mathrm{SV}$ s only grafting at initial $\mathrm{CABG}$ ) and divided them into those receiving (1) 1 or more ITA grafts $(\mathrm{n}=53)$ or $(2)$ only SV grafts $(\mathrm{n}=$ $50)$ at reoperation. Their results in these reasonably matched groups showed a nonsignificant trend for better 5-year survival in patients receiving ITAs $(91.6 \%)$ compared with those receiving SVs $(85.3 \%)$. Despite the small number of patients in their analysis, these authors were able to demonstrate a substantially better event-free survival when ITAs were used at the time of reoperation. 
Variances in ITA use in the initial CABG, redo CABG, or both for both the RA and SV cohorts could have influenced our finding of a superior RA survival. We addressed this concern in our risk-adjusted analysis by appropriately accounting for the combined number and type of grafts in our propensity model and consequently in the risk-adjusted survival comparisons (Figure 3). Additionally, the superior survival of the RA cohort persisted when this population was divided into patients who did or did not receive ITA grafts at reoperation (Figure 2). In a related analysis, Tatoulis and colleagues ${ }^{26}$ compared the results of redo CABG with RA grafting with those of a historical control group undergoing redo CABG with SV grafts, with both groups including patients with or without additional ITA grafts at reoperation. They concluded that the RA use was associated with excellent early results that are equal or superior to those seen with SV grafting. Although they found no significant difference in 3-year unadjusted survival, they were able to achieve total arterial revascularization in $92 \%$ of the RA cohort, ${ }^{26}$ with potential long-term survival benefits. ${ }^{7}$

Limitations of the study include its retrospective and observational nature. Ideally, the question of whether RA versus $\mathrm{SV}$ grafting for redo $\mathrm{CABG}$ will improve long-term outcomes is best addressed in prospective randomized trials.

Second, the possibility of residual confounding factors is possible. However, we believe that the comprehensiveness of the propensity model used in the risk adjustment, including initial CABG grafting and patency data, and the multivariate modeling mitigates this concern.

Third, the cause of death in our patient population is unknown, and consequently the death rate might be independent of cardiac factors. Yet the likelihood that noncardiac deaths explain this risk-adjusted difference in late survival is low.

Lastly, our analysis would have been enhanced substantially if long-term graft patency comparisons were similarly available after the reoperation.

We conclude that the use of RA as opposed to SV grafting in the redo population, with or without concomitant ITA grafts, is associated with a substantial improvement in late survival. This benefit is likely derived from the increased overall number of arterial grafts used for revascularization, which is an important objective for successful surgical treatment.

\section{References}

1. Loop F, Lytle B, Cosgrove D, et al. Influence of the internal-mammary-artery graft on 10-year survival and other cardiac events. N Engl J Med. 1986;314:1-6.

2. Cameron A, Davis KB, Green G, Schaff HV. Coronary bypass surgery with internal-thoracic-artery grafts-effects on survival over a 15 -year period. $N$ Engl $J$ Med. 1996;334:216-9.

3. Lytle BW, Blackstone EH, Sabik JF, Houghtaling P, Loop FD, Cosgrove DM. The effect of bilateral internal thoracic artery grafting on survival during 20 postoperative years. Ann Thorac Surg. 2004;78:2005-12.
4. Rankin JS, Tuttle RH, Wechsler AS, Teichmann TL, Glower DD, Califf RM. Techniques and benefits of multiple internal mammary artery bypass at 20 years of follow-up. Ann Thorac Surg. 2007;83:1008-14.

5. Zacharias A, Habib RH, Schwann TA, Riordan CJ, Durham SJ, Shah A. Improved survival with radial artery versus vein conduits in coronary bypass surgery with left internal thoracic artery to left anterior descending artery grafting. Circulation. 2004;109:1489-96.

6. Schwann TA, Zacharias A, Riordan CJ, Durham SJ, Shah AS, Habib RH. Survival and graft patency following coronary artery bypass grafting with coronary endarterectomy: role of arterial versus vein conduits. Ann Thorac Surg. 2007;84:25-31.

7. Zacharias A, Schwann TA, Riordan CJ, Durham SJ, Shah A, Habib RH. Late results of conventional versus all-arterial revascularization based on internal thoracic and radial artery grafting. Ann Thorac Surg. 2009;87:19-26, e2.

8. Schwann TA, Zacharias A, Riordan CJ, Durham SJ, Shah AS, Habib RH. Sequential radial artery grafts for multi-vessel CABG: 10-year survival and angiography results. Ann Thorac Surg. 2009;88:31-9.

9. Lytle BW, McElroy D, McCarthy P, et al. Influence of arterial coronary bypass grafts on the mortality in coronary reoperations. J Thorac Cardiovasc Surg. 1994; $107: 675-83$.

10. Sabik JF III, Blackstone EH, Houghtaling PL, et al. Is reoperation still a risk factor in coronary artery bypass surgery? Ann Thorac Surg. 2005;80:1719-27.

11. Blackstone EH. Comparing apples to oranges. J Thorac Cardiovasc Surg. 2002; 123:8-15.

12. Harrell FE Jr. Regression modeling strategies: with application to linear models, logistic regression, and survival analysis. New York: Springer-Verlag; 2001.

13. Myers WO, Blackstone EH, Davis K, Foster ED, Kaiser GC. CASS Registry long-term surgical survival. Coronary Artery Surgery Study. J Am Coll Cardiol. 1999;33:488-98.

14. Domanski MJ, Borkowf CB, Campeau L, et al. Prognostic factors for atherosclerosis progression in saphenous vein grafts. J Am Coll Cardiol. 2000; $36: 1877-83$.

15. Christenson JT, Schmuziger M, Simonet F. Reoperative coronary artery bypass procedures: risk factors for early mortality and late survival. Eur J Cardiothorac Surg. 1997;11:129-33.

16. Alexander JH, Hafley G, Harrington RA, et al. Efficacy and safety of edifoligide, an E2F transcription factor decoy, for prevention of vein graft failure following coronary artery bypass graft surgery: PREVENT IV: a randomized controlled trial. JAMA. 2005;294:2446-54.

17. Mishra YK, Collison SP, Malhotra R, et al. Ten-year experience with singlevessel and multivessel reoperative off-pump coronary artery bypass grafting. J Thorac Cardiovasc Surg. 2008;135:527-32.

18. Possati G, Gaudino M, Alessandrini F, et al. Midterm clinical and angiographic results of radial artery grafts used for myocardial revascularization. $J$ Thorac Cardiovasc Surg. 1998;116:1015-21.

19. Desai ND, Cohen EA, Naylor D, Fremes SE. A randomized comparison of radialartery and saphenous-vein coronary bypass grafts. N Engl J Med. 2004;351:2302-9.

20. Buxton BF, Raman JS, Ruengsakulrach P, et al. Radial artery patency and clinical outcomes: five-year interim results of a randomized trial. $J$ Thorac Cardiovasc Surg. 2003; 125:1363-71

21. Collins P, Webb CM, Chong CF, Moat NE, for the Radial Artery Versus Saphenous Vein Patency (RSVP) Trial Investigators. Radial artery versus saphenous vein patency randomized trial: five-year angiographic follow-up. Circulation. 2008; 117:2859-64.

22. Loop FD, Lytle BW, Cosgrove DM, et al. Reoperation for coronary atherosclerosis. Changing practice in 2509 consecutive patients. Ann Surg. 1990;212:378-85.

23. Kaul TK, Fields BL, Wyatt DA, Jones CR, Kahn DR. Reoperative coronary artery bypass surgery: early and late results and management in 1300 patients. J Cardiovasc Surg. 1995;36:303-12.

24. Weintraub WS, Jones EL, Craver JM, et al. In-hospital and long-term outcome after reoperative coronary artery bypass graft surgery. Circulation. 1995;92(suppl II):II50.

25. Dougenis D, Brown AH. Long term results of reoperations for recurrent angina with internal mammary artery versus saphenous vein grafts. Heart. 1998;80:9-13.

26. Tatoulis J, Buxton BF, Fuller JA. The radial artery in reoperative coronary bypass surgery: a 5-year experience. J Card Surg. 2004;19:296-302.

27. Taggart DP. Arterial or venous conduits for redo coronary artery bypass grafting? Heart. 1998;80:1-2. 

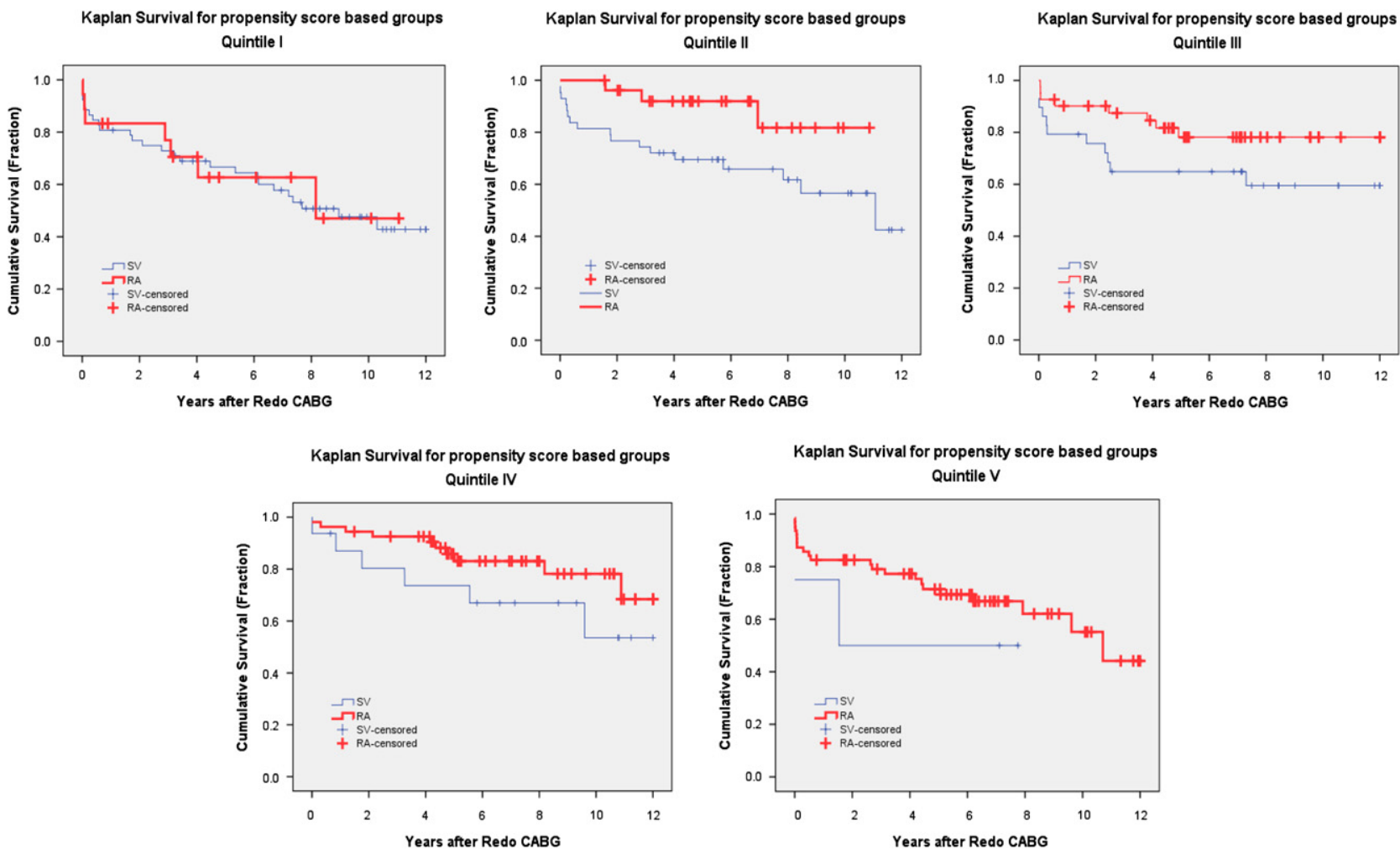

FIGURE E1. Kaplan-Meier comparisons for propensity score quintile groups. A summary of results at 5 and 10 years is also provided in Table 4 of the article. $S V$, Saphenous vein; $R A$, radial artery; $C A B G$, coronary artery bypass grafting.

TABLE E1. Annual volumes of reoperations over the study period

\begin{tabular}{|c|c|c|c|c|c|}
\hline \multirow[b]{2}{*}{$\begin{array}{c}\text { Surgical } \\
\text { year }\end{array}$} & \multicolumn{5}{|c|}{ No. of CABG reoperations } \\
\hline & All & RA cohort & $\begin{array}{c}\text { SV } \\
\text { cohort }\end{array}$ & $\begin{array}{c}\text { Isolated } \\
\text { CABG }\end{array}$ & $\begin{array}{c}\text { CABG } \\
\text { plus }\end{array}$ \\
\hline 1996 & 34 & $12(35 \%)$ & $22(65 \%)$ & 30 & 4 \\
\hline 1997 & 37 & $15(41 \%)$ & $22(59 \%)$ & 34 & 3 \\
\hline 1998 & 35 & $20(57 \%)$ & $15(43 \%)$ & 32 & 3 \\
\hline 1999 & 27 & $12(44 \%)$ & $15(56 \%)$ & 22 & 5 \\
\hline 2000 & 31 & $15(48 \%)$ & $16(52 \%)$ & 28 & 3 \\
\hline 2001 & 48 & $32(67 \%)$ & $16(33 \%)$ & 33 & 15 \\
\hline 2002 & 37 & $23(62 \%)$ & $14(38 \%)$ & 27 & 10 \\
\hline 2003 & 41 & $34(83 \%)$ & $7(17 \%)$ & 32 & 9 \\
\hline 2004 & 25 & $18(72 \%)$ & $7(28 \%)$ & 22 & 3 \\
\hline 2005 & 13 & $7(54 \%)$ & $6(46 \%)$ & 11 & 2 \\
\hline 2006 & 10 & $9(90 \%)$ & $1(10 \%)$ & 6 & 4 \\
\hline 2007 & 9 & $6(67 \%)$ & $3(33 \%)$ & 6 & 3 \\
\hline 1996-2007 & 347 & $203(59 \%)$ & $144(41 \%)$ & $283(82 \%)$ & $64(18 \%)$ \\
\hline
\end{tabular}

Annual Redo CABG volumes: median $=32$ (range, $9-48$ ); $29 \pm 13$ cases per year. This excludes coronary artery bypass grafting reoperations combined with other major cardiovascular operations, such as valve and aortic surgery. $C A B G$, Coronary artery bypass grafting; $C A B G$ plus, coronary artery bypass grafting concomitant with other procedures (eg, carotid endarterectomy, lung operation, or the maze procedure). 
TABLE E2. Grafting data summary from prior or "initial" CABG operation for the reoperative CABG cohort $(\mathbf{n}=347)$

\begin{tabular}{|c|c|c|c|c|c|c|c|c|c|c|c|c|}
\hline $\begin{array}{c}\text { Conduit/ } \\
\text { target }\end{array}$ & LAD & D1 & D2 & Ramus & $\mathrm{CX}$ & OM1 & OM2 & OM3 & RCA & PDA & LVB & $\mathbf{A M}$ \\
\hline All types & 291 & 135 & 6 & 18 & 57 & 128 & 47 & 7 & 143 & 86 & 11 & 3 \\
\hline ITA (any) & 218 & 25 & 1 & 1 & 2 & 3 & 1 & 0 & 11 & 1 & 1 & 1 \\
\hline LITA & 215 & 20 & 1 & 1 & 2 & 2 & 1 & 0 & 0 & 0 & 0 & 0 \\
\hline RITA & 2 & 1 & 0 & 0 & 0 & 1 & 0 & 0 & 11 & 1 & 0 & 1 \\
\hline Free ITA & 1 & 1 & 0 & 0 & 0 & 0 & 0 & 0 & 0 & 0 & 1 & 0 \\
\hline RA & 1 & 4 & 0 & 0 & 1 & 8 & 3 & 0 & 4 & 12 & 1 & 0 \\
\hline SV & 74 & 109 & 5 & 17 & 54 & 117 & 43 & 7 & 128 & 73 & 9 & 2 \\
\hline
\end{tabular}

$C A B G$, Coronary artery bypass grafting; $L A D$, left anterior descending artery; $D 1$ and $D 2$, first and second diagonal arteries; Ramus, ramus intermedius; $C X$, circumflex artery; $O M 1$, $O M 2$, and $O M 3$, first, second, and third obtuse marginal artery; $R C A$, right coronary artery; $P D A$, posterior descending artery; $L V B$, left ventricular branch; $A M$, acute marginal artery; ITA, internal thoracic artery; LITA, left internal thoracic artery; RITA, right internal thoracic artery; RA, radial artery; $S V$, saphenous vein.

TABLE E3. Summary of graft failure ( $>75 \%$ stenosis) data from "initial" CABG for the entire reoperative CABG cohort (n = 347)

\begin{tabular}{|c|c|c|c|c|c|c|c|c|c|c|c|c|}
\hline $\begin{array}{c}\text { Conduit/ } \\
\text { target }\end{array}$ & LAD & D1 & D2 & Ramus & $\mathbf{C X}$ & OM1 & OM2 & OM3 & RCA & PDA & LVB & $\mathbf{A M}$ \\
\hline All types & 96 & 89 & 3 & 12 & 44 & 88 & 35 & 7 & 104 & 64 & 7 & 1 \\
\hline ITA (any) & 45 & 6 & 0 & 1 & 1 & 2 & 0 & 0 & 7 & 0 & 0 & 0 \\
\hline LITA & 44 & 5 & 0 & 1 & 1 & 1 & 0 & 0 & 0 & 0 & 0 & 0 \\
\hline RITA & 0 & 1 & 0 & 0 & 0 & 1 & 0 & 0 & 8 & 0 & 0 & 0 \\
\hline Free ITA & 1 & 0 & 0 & 0 & 0 & 0 & 0 & 0 & 0 & 0 & 0 & 0 \\
\hline RA & 0 & 2 & 0 & 0 & 0 & 7 & 1 & 0 & 3 & 9 & 0 & 0 \\
\hline SV & 50 & 81 & 3 & 11 & 43 & 79 & 34 & 7 & 93 & 55 & 7 & 1 \\
\hline
\end{tabular}

$C A B G$, Coronary artery bypass grafting; $L A D$, left anterior descending artery; $D 1$ and $D 2$, first and second diagonal arteries; Ramus, ramus intermedius; $C X$, circumflex artery; $O M 1$, $O M 2$, and $O M 3$, first, second, and third obtuse marginal artery; $R C A$, right coronary artery; $P D A$, posterior descending artery; $L V B$, left ventricular branch; $A M$, acute marginal artery; ITA, internal thoracic artery; LITA, left internal thoracic artery; RITA, right internal thoracic artery; $R A$, radial artery; $S V$, saphenous vein.

TABLE E4. Grafting data summary from prior or "initial" CABG operation for the reoperative CABG subcohort with saphenous vein and no radial artery grafts $(n=147)$

\begin{tabular}{|c|c|c|c|c|c|c|c|c|c|c|c|c|}
\hline $\begin{array}{c}\text { Conduit/ } \\
\text { target }\end{array}$ & LAD & D1 & D2 & Ramus & CX & OM1 & OM2 & OM3 & RCA & PDA & LVB & $\mathbf{A M}$ \\
\hline All types & 118 & 49 & 3 & 8 & 30 & 46 & 14 & 2 & 67 & 31 & 5 & 1 \\
\hline ITA (any) & 81 & 9 & 0 & 1 & 2 & 0 & 0 & 0 & 6 & 0 & 1 & 0 \\
\hline LITA & 80 & 9 & 0 & 1 & 2 & 0 & 0 & 0 & 0 & 0 & 0 & 0 \\
\hline RITA & 1 & 0 & 0 & 0 & 0 & 0 & 0 & 0 & 6 & 0 & 0 & 0 \\
\hline Free ITA & 0 & 0 & 0 & 0 & 0 & 0 & 0 & 0 & 0 & 0 & 1 & 0 \\
\hline RA & 0 & 3 & 0 & 0 & 1 & 6 & 1 & 0 & 2 & 7 & 1 & 0 \\
\hline$\underline{S V}$ & 37 & 37 & 3 & 7 & 27 & 40 & 13 & 2 & 59 & 24 & 3 & 1 \\
\hline
\end{tabular}

$C A B G$, Coronary artery bypass grafting; $L A D$, left anterior descending artery; $D 1$ and $D 2$, first and second diagonal arteries; Ramus, ramus intermedius; $C X$, circumflex artery; $O M 1$, $O M 2$, and $O M 3$, first, second, and third obtuse marginal artery; $R C A$, right coronary artery; $P D A$, posterior descending artery; $L V B$, left ventricular branch; $A M$, acute marginal artery; ITA, internal thoracic artery; LITA, left internal thoracic artery; RITA, right internal thoracic artery; RA, radial artery; $S V$, saphenous vein. 
TABLE E5. Summary of graft failure ( $>75 \%$ stenosis) data from "initial" CABG for the reoperative CABG subcohort with saphenous vein and no radial artery grafts $(n=147)$

\begin{tabular}{|c|c|c|c|c|c|c|c|c|c|c|c|c|}
\hline $\begin{array}{c}\text { Conduit/ } \\
\text { target }\end{array}$ & LAD & D1 & D2 & Ramus & $\mathbf{C X}$ & OM1 & OM2 & OM3 & RCA & PDA & LVB & $\mathbf{A M}$ \\
\hline All types & 45 & 35 & 3 & 6 & 22 & 36 & 13 & 2 & 49 & 26 & 2 & 1 \\
\hline ITA (any) & 16 & 3 & 0 & 1 & 1 & 0 & 0 & 0 & 5 & 0 & 0 & 0 \\
\hline LITA & 16 & 3 & 0 & 1 & 1 & 0 & 0 & 0 & 0 & 0 & 0 & 0 \\
\hline RITA & 0 & 0 & 0 & 0 & 0 & 0 & 0 & 0 & 5 & 0 & 0 & 0 \\
\hline Free ITA & 0 & 0 & 0 & 0 & 0 & 0 & 0 & 0 & 0 & 0 & 0 & 0 \\
\hline RA & 0 & 2 & 0 & 0 & 0 & 6 & 1 & 0 & 2 & 6 & 0 & 0 \\
\hline SV & 28 & 30 & 3 & 5 & 21 & 30 & 12 & 2 & 42 & 20 & 2 & 1 \\
\hline
\end{tabular}

$C A B G$, Coronary artery bypass grafting; $L A D$, left anterior descending artery; $D 1$ and $D 2$, first and second diagonal arteries; $R a m u s$, ramus intermedius; $C X$, circumflex artery; $O M 1$, $O M 2$, and $O M 3$, first, second, and third obtuse marginal artery; $R C A$, right coronary artery; $P D A$, posterior descending artery; $L V B$, left ventricular branch; $A M$, acute marginal artery; ITA, internal thoracic artery; LITA, left internal thoracic artery; RITA, right internal thoracic artery; RA, radial artery; SV, saphenous vein.

TABLE E6. Grafting data summary from prior or "initial" CABG operation for the reoperative CABG subcohort with radial artery grafts $(\mathbf{n}=\mathbf{2 0 0})$

\begin{tabular}{|c|c|c|c|c|c|c|c|c|c|c|c|c|}
\hline $\begin{array}{c}\text { Conduit/ } \\
\text { target }\end{array}$ & LAD & D1 & D2 & Ramus & CX & OM1 & OM2 & OM3 & RCA & PDA & LVB & $\mathbf{A M}$ \\
\hline All types & 175 & 86 & 3 & 10 & 27 & 82 & 33 & 5 & 76 & 55 & 6 & 2 \\
\hline ITA (any) & 137 & 13 & 1 & 0 & 0 & 3 & 1 & 0 & 5 & 1 & 0 & 1 \\
\hline LITA & 135 & 11 & 1 & 0 & 0 & 2 & 1 & 0 & 0 & 0 & 0 & 0 \\
\hline RITA & 1 & 1 & 0 & 0 & 0 & 1 & 0 & 0 & 5 & 1 & 0 & 1 \\
\hline Free ITA & 1 & 1 & 0 & 0 & 0 & 0 & 0 & 0 & 0 & 0 & 0 & 0 \\
\hline RA & 1 & 1 & 0 & 0 & 0 & 2 & 2 & 0 & 2 & 5 & 0 & 0 \\
\hline SV & 37 & 72 & 2 & 10 & 27 & 77 & 30 & 5 & 69 & 49 & 6 & 1 \\
\hline
\end{tabular}

$C A B G$, Coronary artery bypass grafting; $L A D$, left anterior descending artery; $D 1$ and $D 2$, first and second diagonal arteries; Ramus, ramus intermedius; $C X$, circumflex artery; $O M 1$, $O M 2$, and $O M 3$, first, second, and third obtuse marginal artery; $R C A$, right coronary artery; $P D A$, posterior descending artery; $L V B$, left ventricular branch; $A M$, acute marginal artery; ITA, internal thoracic artery; LITA, left internal thoracic artery; RITA, right internal thoracic artery; $R A$, radial artery; $S V$, saphenous vein.

TABLE E7. Summary of graft failure ( $>75 \%$ stenosis) data from "initial” CABG for the reoperative CABG subcohort with radial artery grafts $(\mathbf{n}=\mathbf{2 0 0})$

\begin{tabular}{|c|c|c|c|c|c|c|c|c|c|c|c|c|}
\hline $\begin{array}{c}\text { Conduit/ } \\
\text { target }\end{array}$ & LAD & D1 & D2 & Ramus & CX & OM1 & OM2 & OM3 & RCA & PDA & LVB & $\mathbf{A M}$ \\
\hline All types & 51 & 54 & 0 & 6 & 22 & 52 & 22 & 5 & 55 & 38 & 5 & 0 \\
\hline ITA (any) & 30 & 3 & 0 & 0 & 0 & 2 & 0 & 0 & 3 & 0 & 0 & 0 \\
\hline LITA & 29 & 2 & 0 & 0 & 0 & 1 & 0 & 0 & 0 & 0 & 0 & 0 \\
\hline RITA & 0 & 1 & 0 & 0 & 0 & 1 & 0 & 0 & 2 & 0 & 0 & 0 \\
\hline Free ITA & 1 & 0 & 0 & 0 & 0 & 0 & 0 & 0 & 0 & 0 & 0 & 0 \\
\hline RA & 0 & 0 & 0 & 0 & 0 & 1 & 0 & 0 & 1 & 3 & 0 & 0 \\
\hline SV & 23 & 51 & 0 & 6 & 22 & 49 & 22 & 5 & 51 & 35 & 5 & 0 \\
\hline
\end{tabular}

$C A B G$, Coronary artery bypass grafting; $L A D$, left anterior descending artery; $D 1$ and $D 2$, first and second diagonal arteries; Ramus, ramus intermedius; $C X$, circumflex artery; $O M 1$, $O M 2$, and $O M 3$, first, second, and third obtuse marginal artery; $R C A$, right coronary artery; $P D A$, posterior descending artery; $L V B$, left ventricular branch; $A M$, acute marginal artery; ITA, internal thoracic artery; LITA, left internal thoracic artery; RITA, right internal thoracic artery; $R A$, radial artery; $S V$, saphenous vein. 
TABLE E8. Grafting data summary from the redo operation for the entire study CABG reoperation cohort $(\mathbf{n}=347)$

\begin{tabular}{|c|c|c|c|c|c|c|c|c|c|c|c|c|c|}
\hline $\begin{array}{c}\text { Conduit/ } \\
\text { target }\end{array}$ & LAD & D1 & D2 & Ramus & CX & OM1 & OM2 & OM3 & RCA & PDA & LVB & $\mathbf{A M}$ & All targets \\
\hline All types & 206 & 125 & 2 & 41 & 28 & 163 & 83 & 22 & 77 & 168 & 29 & 6 & 950 \\
\hline ITA (any) & 114 & 16 & 1 & 4 & 1 & 6 & 1 & 0 & 10 & 6 & 1 & 1 & 161 \\
\hline LITA & 66 & 5 & 1 & 1 & 1 & 1 & 0 & 0 & 0 & 0 & 0 & 0 & 75 \\
\hline RITA & 40 & 6 & 0 & 1 & 0 & 3 & 0 & 0 & 9 & 5 & 0 & 1 & 65 \\
\hline Free ITA & 8 & 5 & 0 & 2 & 0 & 2 & 1 & 0 & 1 & 1 & 1 & 0 & 21 \\
\hline RA & 41 & 35 & 0 & 18 & 11 & 68 & 22 & 6 & 14 & 37 & 8 & 0 & 260 \\
\hline SV & 51 & 74 & 1 & 19 & 16 & 89 & 60 & 16 & 53 & 125 & 20 & 5 & 529 \\
\hline
\end{tabular}

$C A B G$, Coronary artery bypass grafting; $L A D$, left anterior descending artery; $D 1$ and $D 2$, first and second diagonal arteries; Ramus, ramus intermedius; $C X$, circumflex artery; $O M 1$, $O M 2$, and $O M 3$, first, second, and third obtuse marginal artery; $R C A$, right coronary artery; $P D A$, posterior descending artery; $L V B$, left ventricular branch; $A M$, acute marginal artery; ITA, internal thoracic artery; LITA, left internal thoracic artery; RITA, right internal thoracic artery; RA, radial artery; $S V$, saphenous vein.

TABLE E9. Results of proportional hazard Cox regression based on 23 forced patient covariates in addition to RA graft use and RA-use propensity score

\begin{tabular}{|c|c|c|c|c|c|c|c|}
\hline \multirow{2}{*}{$\frac{\text { Variables }}{\text { RA graft (vs SV) }}$} & \multirow{2}{*}{$\frac{\mathbf{B}}{-1.05}$} & \multirow{2}{*}{$\frac{\mathbf{S E}}{0.41}$} & \multirow{2}{*}{$\frac{\text { Wald }}{6.52}$} & \multirow{2}{*}{$\frac{\text { Significance }(\boldsymbol{P} \text { value })}{.011}$} & \multirow{2}{*}{$\frac{\text { Risk ratio }}{0.35}$} & \multicolumn{2}{|c|}{$95 \%$ CI for $\operatorname{Exp}(B)$} \\
\hline & & & & & & 0.16 & 0.78 \\
\hline $\begin{array}{l}\text { RA-use propensity } \\
\text { score (logit) }\end{array}$ & 0.14 & 0.21 & 0.42 & .515 & 1.15 & 0.76 & 1.72 \\
\hline \multicolumn{8}{|l|}{ Covariates (continuous) } \\
\hline Age (y) & 0.05 & 0.02 & 10.58 & .001 & 1.05 & 1.02 & 1.08 \\
\hline $\begin{array}{l}\text { Body mass } \\
\text { index }\left(\mathrm{kg} / \mathrm{m}^{2}\right)\end{array}$ & 0.02 & 0.03 & 0.42 & .516 & 1.02 & 0.96 & 1.08 \\
\hline Ejection fraction $(\%)$ & -0.04 & 0.02 & 5.72 & .017 & 0.96 & 0.94 & 0.99 \\
\hline \multicolumn{8}{|l|}{ Covariates (categorical) } \\
\hline Diabetes & 0.31 & 0.31 & 1.01 & .315 & 1.36 & 0.74 & 2.50 \\
\hline Insulin dependence & 0.17 & 0.42 & 0.15 & .696 & 1.18 & 0.51 & 2.71 \\
\hline Renal failure & 1.97 & 0.57 & 11.92 & .001 & 7.20 & 2.35 & 22.10 \\
\hline High cholesterol & 0.24 & 0.35 & 0.46 & .499 & 1.27 & 0.64 & 2.51 \\
\hline Hypertension & -0.02 & 0.41 & 0.00 & .960 & 0.98 & 0.44 & 2.17 \\
\hline $\begin{array}{l}\text { Peripheral vascular } \\
\text { disease }\end{array}$ & 0.10 & 0.35 & 0.08 & .774 & 1.11 & 0.56 & 2.19 \\
\hline Cerebrovascular disease & -0.10 & 0.31 & 0.10 & .751 & 0.91 & 0.49 & 1.67 \\
\hline Chronic lung disease & -0.04 & 0.32 & 0.01 & .909 & 0.96 & 0.51 & 1.82 \\
\hline $\begin{array}{l}\text { History of myocardial } \\
\text { infarction }\end{array}$ & -0.09 & 0.28 & 0.11 & .744 & 0.91 & 0.53 & 1.58 \\
\hline Congestive heart failure & 0.06 & 0.42 & 0.02 & .887 & 1.06 & 0.46 & 2.43 \\
\hline Arrhythmia & -0.09 & 0.35 & 0.06 & .802 & 0.92 & 0.46 & 1.82 \\
\hline NYHA class III/IV & 0.67 & 0.37 & 3.23 & .072 & 1.96 & 0.94 & 4.08 \\
\hline Left main disease & 0.48 & 0.30 & 2.62 & .105 & 1.62 & 0.90 & 2.90 \\
\hline $\begin{array}{l}\text { Vessel disease } \\
\quad(\text { reference=1-vessel } \\
\quad \text { disease })\end{array}$ & & & 0.55 & .759 & & & \\
\hline 2-Vessel disease & -0.02 & 0.71 & 0.00 & .975 & 0.98 & 0.24 & 3.95 \\
\hline 3-Vessel disease & -0.29 & 0.64 & 0.20 & .656 & 0.75 & 0.21 & 2.65 \\
\hline Emergency & 0.17 & 0.78 & 0.05 & .826 & 1.19 & 0.26 & 5.52 \\
\hline Off-pump CABG & -0.19 & 0.54 & 0.12 & .732 & 0.83 & 0.29 & 2.41 \\
\hline Other cardiac procedure & -0.16 & 0.52 & 0.09 & .767 & 0.86 & 0.31 & 2.39 \\
\hline $\begin{array}{l}\text { Other noncardiac } \\
\text { procedure }\end{array}$ & 0.85 & 0.41 & 4.34 & .037 & 2.34 & 1.05 & 5.21 \\
\hline $\begin{array}{l}\text { Patent LITA (previous } \\
\text { CABG) }\end{array}$ & -0.15 & 0.30 & 0.24 & .625 & 0.86 & 0.48 & 1.55 \\
\hline $\begin{array}{l}\text { No. of arterial } \\
\text { grafts (total) }\end{array}$ & 0.26 & 0.19 & 1.97 & .161 & 1.30 & 0.90 & 1.89 \\
\hline
\end{tabular}

